\title{
Role of intravenous tranexamic acid on cesarean blood loss: a prospective randomized study
}

\begin{abstract}
Background: Postpartum hemorrhage (PPH) is a major cause of maternal mortality globally. Tranexamic acid (an anti-fibrinolytic agent) is a novel approach to prevent this dreadful complication.

Aim of the work: The aim was to study the efficacy and safety of intravenous tranexamic acid in reducing blood loss during and after the lower segment cesarean section.

Patients and methods: In this prospective randomized clinical study, 200 mothers scheduled for elective CS were randomly selected and divided into two groups (study and control) of 100 each. The study group received $1 \mathrm{~g} \mathrm{IV}$ tranexamic acid immediately before LSCS. And the control group received $30 \mathrm{ml}$ of $5 \%$ glucose, all mothers received 10 units of oxytocin in $500 \mathrm{ml}$ of normal saline.
\end{abstract}

Results: The mean intraoperative and postpartum blood loss was significantly lower in the study group than the control group.

Conclusion: Preoperative IV tranexamic acid significantly reduced blood loss during elective CS without any significant adverse effects.
Volume 8 Issue 3 - 2019

\author{
Manal A Farahat,' Heba nageeb ${ }^{2}$ \\ 'Master degree of obstetrics and gynecologic Mansura hospital, \\ Egypt \\ ${ }^{2}$ Department of Obstetrics and Gynecology, Tanta University, \\ Egypt
}

Correspondence: Manal A Farahat, Department of Obstetrics and Gynecology, Faculty of medicine, Tanta University, Egypt, Email majid.eslami@modares.ac.ir

Received: May 06, 2019 | Published: June II, 2019

Keywords: postpartum hemorrhage, tranexamic acid, cesarean section

\section{Introduction}

Cesarean section (CS) rates nowadays is about 25 to $30 \%$ all over the world and has many complications if compared with vaginal delivery, primary and secondary postpartum hemorrhage constitute about $(20 \%)$ of these complications. It also associated with increased rate of maternal mortality and morbidity, so it is important to reduce bleeding during and after Cesarean section (CS) delivery. ${ }^{1}$ Postpartum hemorrhage (PPH) is blood loss of $\geq 500 \mathrm{~mL}$ after vaginal delivery, or $\geq 1000 \mathrm{~mL}$ after caesarean section. However, if pre-existing bad health condition as cardiac disease or severe anemia, blood loss of as little as $200 \mathrm{~mL}$ is considered life-threatening. ${ }^{2}$ In Cesarean delivery, there is $10 \%$ decrease in hematocrit value with $6 \%$ incidence of blood transfusion compared with $4 \%$ only in vaginal delivery. Multiple medications, such as methylergonovine, oxytocin, prostaglandin F2 $\alpha$, and misopristol, are life-saving to control bleeding in CS..$^{3-5}$ TXA is a synthetic derivative of lysine High affinity for lysine binding sites on plasminogen to block plasmin from binding and degrading linked fibrin. TA may enhance the effectiveness of endogenous hemostatic mechanism. ${ }^{6,7}$ TA can be used by intravenous rout to reduce hemorrhage in many surgical operations. ${ }^{8,9}$ In gynecology, especially idiopathic menorrhagia, tranexamic acid was considered well-tolerated and effective oral treatment. In obstetrics, it also can be used in different bleeding conditions (placenta previa and placental abruption). ${ }^{10}$

\section{Patients and methods}

A randomized, placebo-controlled, clinical study, during the period from June 2018 till March 2019, and after Institutional Ethical Committee approved the protocol. The study carried out on clinically free singleton antenatal women (20-35 years old),
Primary, 2nd or 3rd gravida, more than or equal 38 weeks gestation planed for elective CS with normal range of platelet count. If the pregnant women have allergy to tranexamic acid or with any risk factor for postpartum hemorrhage (PPH) (sever pre-eclampsia, polyhydramnios, fetal macrosomia, multiple gestation, preterm labor, antepartum hemorrhage (placenta previa or accidental hemorrhage), abnormal placentation, fibroid uterus, history of uterine atony or postpartum hemorrhage, and emergency CS, were excluded from the study along with women suffering from any blood disease, anemia (hemoglobin $<10 \mathrm{~g} \%$ ) and any medical or surgical complain. Initially we recruited 220 women admitted for elective CS, 16 were excluded due to different causes (vaginal delivery 7 cases, emergency LSCS 4 cases, fetal distress 2 cases, scar tenderness 3 cases) 4 patients refused to give consent for the study, finally 200 women were allocated for the study and randomly divided into two equal groups (Figure 1).

\section{Patients involved in this study were subdivided into two groups}

Group A (Study Group): Included one hundred (100) patients. They were given tranexamic acid $(1 \mathrm{~g} / 10 \mathrm{~mL})$ diluted in $20 \mathrm{~mL}$ of $5 \%$ glucose and administrated slowly intravenous in a period of 5-minute at least 10 minutes before skin incision.

Group 2 (placebo Group): Included one hundred (100) patients, received $30 \mathrm{~mL}$ of $5 \%$ glucose. After CS both groups were taken bolus intra venous $5 \mathrm{IU}$ of oxytocin, followed by oxytocin infusion (30 IU in $500 \mathrm{ml}$ lactated Ringer's solution in a period of four hours, also $1 \mathrm{~g}$ cefazoline antibiotic diluted in $20 \mathrm{~mL}$ normal saline was given slowly intravenous. Vital signs (pulse, blood pressure and respiratory rate) were recorded before operation, after placental delivery, 1 and 2 hour post-partum. Prothrombine time (PT), activated partial 
thromboplastine time (aPTT), and blood picture (CBC) were recorded before CS operation and 24 hours later. Volume of blood loss was estimated by the difference in hematocrit values before and one day after cesarean delivery by these two formulas.

a) Estimated blood volume $(\mathrm{EBV})$ in $\mathrm{mL}=$ the woman's weight in $\mathrm{kg} \times 85 .{ }^{11}$

b) Estimated blood loss $=(\mathrm{EBV}) \times \frac{\text { preop hematocrit }- \text { postop hematocrit }}{{ }^{11}}$
Liver function tests (serum ALT, AST and bilirubin) and renal function tests (serum creatinine and urea) was evaluated day before and day after CS to assess TA side effects. After delivery, $500 \mathrm{~mL}$ normal saline with $10 \mathrm{IU}$ were infused intravenous during 30 minutes duration, followed by three bottles of IV fluid with 5 IU in each, one bottle every four hours. After that, further oxytocin was given if required.

preop hematocrit

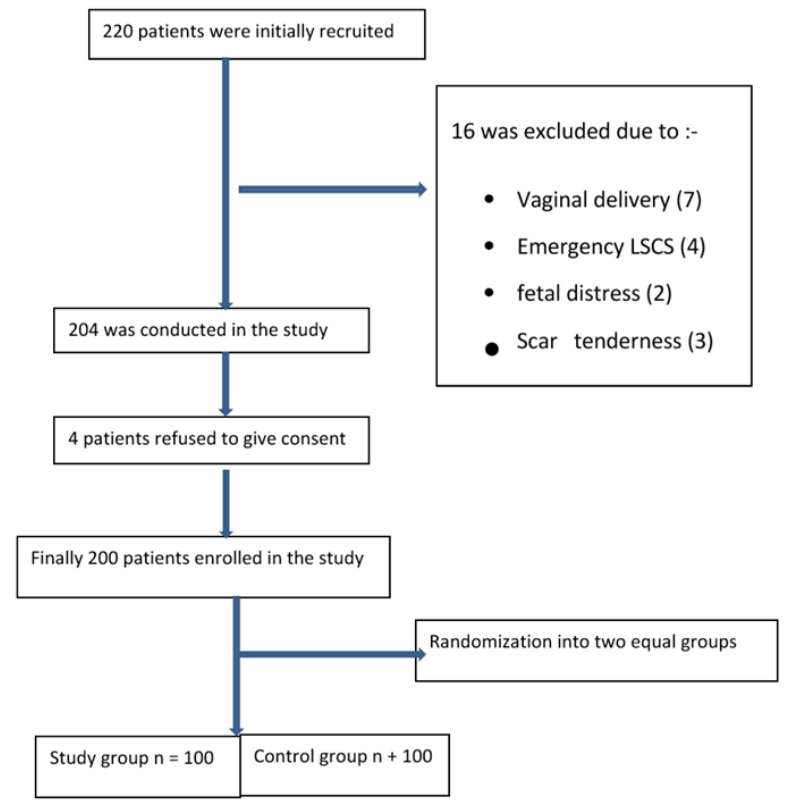

Figure I Summary of study design.

\section{Results}

The results of this study are summarized in 6 tables.

Table 1 Shows that the study and placebo groups were equally matched with respect to demographic characteristics (age, weight, gravidity ), period of gestation at which CS was done, preoperative hemoglobin \% with no statistically significant difference between both groups.

Table I Clinical data of the tranexamic acid (study) and placebo groups

\begin{tabular}{llll}
\hline & $\begin{array}{l}\text { Study Group } \\
(\mathbf{n} \mid 00)\end{array}$ & $\begin{array}{l}\text { Placebo Group } \\
(\mathbf{n}=100)\end{array}$ & P value \\
\hline Age & $29.71 \pm 4.18$ & $29.75 \pm 4.01$ & $0.961(\mathrm{NS})$ \\
Weight & $82.67 \pm 9.21$ & $81.33 \pm 8.75$ & $0.457(\mathrm{NS})$ \\
Gravida I & $80(80 \%)$ & $76(76 \%)$ & $0.759(\mathrm{NS})$ \\
$2 \mathrm{nd}$ & $112(112 \%)$ & $124(124 \%)$ & $0.579(\mathrm{NS})$ \\
3 rd & $8(8 \%)$ & $0(0 \%)$ & $0.51 \mathrm{I}(\mathrm{NS})$ \\
$\begin{array}{l}\text { Gestation } \\
\text { (weeks) }\end{array}$ & $38.92+/-1.38$ & $39.02+/-1.42$ & $0.722(\mathrm{NS})$ \\
Hb (g\%) & $10.33+/-1.26$ & $10.80+/-1.34$ & $0.05(\mathrm{NS})$ \\
\hline
\end{tabular}

Table 2 shows vital signs (pulse, respiratory rate (RR), or blood pressure (SBP and DBP) before, immediately after placental delivery, 1 hour and 2 hours after CS between the study and placebo groups with no statistically significant difference between study and control groups.

Table 3 Demonstrates comparison between Pre-operative and postoperative PT(s), A PTT(s), ALT (IU/L), AST (IU/L), serum Creatinine $(\mathrm{mg} / \mathrm{dl})$, serum Urea $(\mathrm{mg} / \mathrm{dl})$ and Platelet count in study and control group. a comparison between study-placebo preoperative (p1), study-placebo postoperative (p2), comparison between pre and post-operative study group ( $\mathrm{p} 3)$, comparison between pre and postoperative placebo group (p4). There was no statistically significant difference in all previous parameters between both groups.

Table 4 Exhibits Comparison between Pre-operative and postoperative $\mathrm{HCV} \% \mathrm{P} 1=$ a comparison between study-placebo preoperative, (p2) study-placebo postoperative, (p3) pre and postoperative study group and (p4) pre and post-operative placebo group The mean postoperative hematocrit level (HCT\%) in the TA group was (31.8 \pm 1.5$)$ which was higher than those of the placebo group $(29.1 \pm 1)$ with statistically significant difference $p$ value $<0.001$, on the other hand in comparing the mean hematocrit level HCT\% in the 
study group pre and post- operative, it was $(33 \pm 3.7) \&(31.8 \pm 1.5)$ respectively with no statistically significant difference $P$ value 0.02

Table 5 Reveals that the mean estimated blood loss was
$(599.9 \pm 206.4 \mathrm{~mL})$ in the study group which is markedly lower than the placebo group $(780.7 \pm 215.7 \mathrm{~mL})$ with statistically significant difference. $P$ value $\leq 0.001$

Table 2 Vital signs before and immediately after placental delivery and I and 2 Hours after CS in the Study (Tranexamic) and Placebo Groups

\begin{tabular}{|c|c|c|c|c|c|c|c|c|c|c|c|c|}
\hline & \multicolumn{3}{|c|}{ Before placental delivery } & \multicolumn{3}{|c|}{$\begin{array}{l}\text { Immediately after placental } \\
\text { delivery }\end{array}$} & \multicolumn{3}{|c|}{$\begin{array}{l}\text { One hour after placental } \\
\text { delivery }\end{array}$} & \multicolumn{3}{|c|}{$\begin{array}{l}\text { Two hours after placental } \\
\text { delivery }\end{array}$} \\
\hline & Study & Placebo & $\mathbf{p}$ & Study & Placebo & $\mathbf{P}$ & Study & Placebo & $\mathbf{p}$ & Study & Placebo & $\mathbf{p}$ \\
\hline Pulse & 90.12 & 92.4 & 0.44 & 91.6 & 90.4 & 0.546 & 81.2 & 80.2 & 0.39 & 79.4 & 79.7 & 0.83 \\
\hline (beat/min) & \pm 11.16 & \pm 9.34 & (NS) & \pm 13.3 & \pm 12 & (NS) & \pm 7.93 & \pm 8.15 & (NS) & \pm 10.3 & \pm 10.3 & (NS) \\
\hline \multirow[t]{2}{*}{$\begin{array}{l}\text { RR (breaths/ } \\
\text { min) }\end{array}$} & 19.04 & 21.48 & 0.35 & 19.8 & 19 & 0.755 & 20.2 & 19.6 & 0.38 & 19.3 & 19.3 & 0.87 \\
\hline & \pm 4.86 & \pm 2.99 & (NS) & \pm 2.14 & \pm 2.1 & (NS) & \pm 6.7 & \pm 2.3 & (NS) & \pm 1.9 & \pm 2 & (NS) \\
\hline \multirow[t]{2}{*}{ SBP (mmHg) } & 120.6 & 125.2 & 0.75 & 117.5 & 117 & 0.836 & 116.3 & 113.3 & 0.22 & II4.8 & 113.2 & 0.45 \\
\hline & \pm 11.04 & \pm 12.02 & (NS) & \pm 11.97 & \pm 12.1 & (NS) & \pm 15.5 & \pm 16.5 & (NS) & \pm 11.92 & \pm 15.4 & (NS) \\
\hline \multirow[t]{2}{*}{$\begin{array}{l}\mathrm{DBP} \\
(\mathrm{mmHg})\end{array}$} & 76.04 & 81.28 & 0.68 & 65.4 & 67.4 & 0.216 & 72.3 & 72 & 0.83 & 72.2 & 72.6 & 0.75 \\
\hline & \pm 10.12 & \pm 9.73 & (NS) & $\pm \mid 1.3$ & \pm 11.3 & (NS) & $\pm 1 \mid .2$ & \pm 9.7 & (NS) & \pm 10.2 & \pm 7.7 & (NS) \\
\hline
\end{tabular}

Table 3 Comparison between Pre-operative and postoperative PT(s), A PTT(s), ALT (IU/L), AST (IU/L), serum Creatinine (mg/dl), serum Urea (mg/dl) and Platelet count in study and control group

\begin{tabular}{|c|c|c|c|c|c|c|c|c|c|}
\hline & & Pre-operative & & $\mathbf{P I}$ & postoperative & & $\mathbf{P 2}$ & P3 & P4 \\
\hline & & $\begin{array}{l}\text { Study } \\
\text { Group } \\
(n=100)\end{array}$ & Placebo Grou & $(n=100)$ & $\begin{array}{l}\text { Study Group } \\
(n=100)\end{array}$ & Placebo Grou & $p(n=100)$ & & \\
\hline \multirow[t]{2}{*}{$\mathrm{PT}(\mathrm{s})$} & Mean \pm SD & & $11.9 \pm 0.3$ & 0.94 & $11.8 \pm 0.4$ & $11.8 \pm 0.4$ & I & 0.21 & 0.16 \\
\hline & & $11.9 \pm 0.4$ & & (NS) & & & (NS) & (NS) & (NS) \\
\hline A PTT(s) & Mean \pm SD & $31.7 \pm 2.6$ & $32.3 \pm 2.8$ & 0.27 (NS) & $32.4 \pm 2$ & $32.7 \pm 2.6$ & $\begin{array}{l}0.52 \\
\text { (NS) }\end{array}$ & 0.13 (NS) & 0.46 (NS) \\
\hline ALT (IU/L) & Mean \pm SD & $17 \pm 6.58$ & $|8.9 \pm 8.6|$ & 0.22 (NS) & $18.47 \pm 6.7$ & $20.75 \pm 8.32$ & 0.13 & 0.27 (NS) & $0.28(\mathrm{NS})$ \\
\hline AST (IU/L) & Mean \pm SD & $18.5 \pm 8.6$ & $20.5 \pm 9.5$ & 0.27 (NS) & $18.23 \pm 7.9$ & $21.23 \pm 9.23$ & $\begin{array}{l}0.08 \\
\text { (NS) }\end{array}$ & 0.87 (NS) & 0.69 (NS) \\
\hline $\begin{array}{l}\text { serum } \\
\text { Creatinine (mg/ } \\
\text { dl) }\end{array}$ & Mean \pm SD & $0.84 \pm 0.17$ & $0.81 \pm 0.16$ & 0.36 (NS) & $0.88 \pm 0.19$ & $0.87 \pm 0.18$ & $\begin{array}{l}0.59 \\
\text { (NS) }\end{array}$ & 0.26 (NS) & 0.08 (NS) \\
\hline $\begin{array}{l}\text { serum Urea } \\
(\mathrm{mg} / \mathrm{dl})\end{array}$ & Mean \pm SD & $28.3 \pm 5.14$ & $30.23 \pm 6.17$ & 0.09 (NS) & $29.9 \pm 5.25$ & $31.33 \pm 5.76$ & $\begin{array}{l}0.24 \\
\text { (NS) }\end{array}$ & 0.12 (NS) & 0.39 (NS) \\
\hline Platelet count & Mean \pm SD & $210,000 \pm 0.62$ & $216,000 \pm 0.62$ & 0.59 (NS) & $205000 \pm 0.48$ & $204000 \pm 0.46$ & $\begin{array}{l}0.70 \\
\text { (NS) }\end{array}$ & 0.65 (NS) & 0.89 (NS) \\
\hline
\end{tabular}

N.B: $\mathrm{PI}=$ comparison between study-placebo preoperative, $\mathrm{P} 2=$ comparison between study-placebo postoperative, $\mathrm{P} 3=$ comparison between pre and postoperative study group, $\mathrm{P} 4=$ comparison between pre and post-operative placebo group. 
Table 4 Comparison between Pre-operative and postoperative HCT (\%)

\begin{tabular}{|c|c|c|c|c|c|c|c|c|}
\hline & \multicolumn{2}{|l|}{ Pre-operative } & \multirow{2}{*}{ P I } & \multicolumn{2}{|c|}{ Postoperative HCT } & \multirow{2}{*}{$\mathbf{P 2}$} & \multirow{2}{*}{ P3 } & \multirow{2}{*}{ P4 } \\
\hline & $\begin{array}{l}\text { Study Group } \\
(n=100)\end{array}$ & $\begin{array}{l}\text { Placebo } \\
\text { Group } \\
(n=100)\end{array}$ & & $\begin{array}{l}\text { Study Group } \\
(n=100)\end{array}$ & $\begin{array}{l}\text { Placebo Group } \\
(n=100)\end{array}$ & & & \\
\hline $\begin{array}{l}\text { Mean } \pm \\
\text { SD }\end{array}$ & $33 \pm 3.7$ & $32.9 \pm 1.6$ & 0.54 (NS) & $31.8 \pm 1.5$ & $29.1 \pm 1$ & $\leq 0.00 I^{*}$ & $0.02(\mathrm{NS})$ & $\leq 0.00 I^{*}$ \\
\hline
\end{tabular}

$P \leq 0.00$ I is statistically significant.

Table 5 Estimated blood loss $(\mathrm{mL})$

\begin{tabular}{llll}
\hline & Study Group $(\mathbf{n}=\mathbf{5 0})$ & Placebo Group $(\mathbf{n}=\mathbf{5 0})$ & $\mathbf{P}$ \\
\hline Mean \pm SD & $599.9 \pm 206.4$ & $780.7 \pm 215.7$ & $\leq 0.00 I^{*}$ \\
\hline
\end{tabular}

$P \leq 0.00$ I is statistically significant.

Table 6 tranexamic acid adverse reactions Nausea, vomiting \& diarrhea occurred in $18,8,2$ cases respectively in the study group \& 5 , 3,0 cases respectively in the placebo group. None of the subjects had any evidence of thrombosis. No statistically significant difference.

Table 6 Comparison of adverse drug reaction in both groups

\begin{tabular}{llll}
\hline & $\begin{array}{l}\text { Study Group } \\
(\mathbf{n = 0} \mid \mathbf{0})\end{array}$ & $\begin{array}{l}\text { Placebo } \\
\text { Group }(\mathbf{n = 0} \mid \mathbf{0})\end{array}$ & $\mathbf{p}$ \\
\hline Nausea & 18 & 5 & $0.55(\mathrm{NS})$ \\
Vomiting & 8 & 3 & $\mathrm{I}(\mathrm{NS})$ \\
Diarrhea & 2 & 0 & $\mathrm{I}(\mathrm{NS})$ \\
$\begin{array}{l}\text { Signs of } \\
\text { thrombosis }\end{array}$ & 0 & 0 & - \\
\hline
\end{tabular}

\section{Discussion}

The most important finding of this study is that, blood loss was $599.9 \pm 206.4 \mathrm{~mL}$ in the study group in comparison to $780.7 \pm 215.7$ $\mathrm{ml}$ in the control group. Which means reduction in blood loss by approximately $23 \%(\mathrm{P}=0.001)$. As regard extra need of $10 \mathrm{IU}$ oxytocin, only three women in the study group compared to twelve in control group. In consistent with the present study, Movafegh. used $10 \mathrm{mg} / \mathrm{kg}$ of TA before skin incision by 20 minutes. Mean blood loss was $(329.5 \pm 39.6$ versus $545.7 \pm 94.4 \mathrm{~mL})$ in study and control groups respectively with statistically significant difference $\mathrm{P}<0.001$ ), also with statistically significant smaller doses of oxytocin $(29 \pm 5.8$ vs. $43 \pm 5.4$ units $\mathrm{P}=0.001 .^{12}$ Comparable study carried out by Gai. ${ }^{13}$ in China showed that tranexamic acid significantly reduced bleeding during and two hours after delivery by $30 \%$ in comparison to control group also postpartum hemorrhage was markedly decreased by $25.7 \%$ as it occurred only in 22 cases versus 35 cases in control group. $\mathrm{P}$ value $=0.029$ these findings correlated well with the current study and also in Leila Sekhavat, ${ }^{14}$ Baird EJ ${ }^{15}$ \& Bresnoc. ${ }^{16}$ In the current study, no statistically significant difference was found in vital signs either before or immediately after delivery of the placenta, 1 or 2 hours after CS, between the two studied groups, which is consistent with Movafegh et al., ${ }^{12}$ and Gai et al., ${ }^{13}$ Also there was no statistically significant changes in $\mathrm{CBC}, \mathrm{PT}$, aPTT, liver or renal function tests after TA administration, this is inconsistent with Baird $\mathrm{EJ}^{15}$ Bresnoc et al., ${ }^{16} \mathrm{Gai},{ }^{13}$ Gohel et al., ${ }^{17}$ Sekhavat et al. ${ }^{14}$ and Yang et al., ${ }^{18}$ Pregnant women have about five to six folds risk of thrombotic complications than non-pregnant women, ${ }^{19}$ especially in post-partum period after CS in women with TA administration. TA appears in cord blood nearly at the same level of maternal blood as it crosses the placenta; also it appears in breast milk but in very low amount, 1/100 of that in maternal blood. $_{20}$ In spite of that, patients under antifibrinolytic agents treatment, have an increased incidence of thrombotic events, there is no statistically significant increase risk in those with TA treatment. ${ }^{21}$ Svanberg et al., ${ }^{22}$ treated 67 cases $t$ by tranexamic acid due to abruptio placenta, no thrombosis occurred or any side effect in form of nausea, vomiting, diarrhea was observed in any patient. Bekassy and Astedt $^{23}$ included 3014 women including 45 pregnant women $\&$ gave tranexamic acid to prevent bleeding at conization of cervix, thromboembolic episodes were absent and no side effects reported. Baird $\mathrm{EJ}^{15}$ A study of 400 pregnant women with normal vaginal deliveries who received tranexamic acid during labor; no thrombosis nor significant adverse effects occurred. Similar results were found in the study of Gohel et al., ${ }^{17}$ Sekhavat et al., ${ }^{14}$ and Gai et al., ${ }^{13}$ At the same time, the current results were similar with previous studies of Bresnoc, ${ }^{16}$ Svanberg et al. ${ }^{22}$ Bekassy and Astedt, ${ }^{23}$ Baird EJ, ${ }^{15}$ Gai et al., ${ }^{13}$ Gohel et al., ${ }^{17}$ and Sekhavat et al., ${ }^{14}$.

\section{Conclusion}

Intravenous Tranexamic Acid was associated with a reduction in intraoperative blood loss among pregnant women undergoing cesarean section and can be safely used without any evident risk of thrombosis. The main limitation of the current study, that we excluded all high risk patients for post-partum hemorrhage.

\section{Acknowledgments}

None.

\section{Conflict of Interest}

The author declares there no conflict of interest here. 


\section{References}

1. Kambo I, Bedi N, Dhillon BS, et al. A critical appraisal of cesarean section at teaching hospitals in India. Int J Gyneacol Obstet. 2002;79(2):151158 .

2. ACOG. Practice Bulletin No183: postpartum hemorrhage. Obstet Gynecol. 2017;130(4):e168-e186.

3. Güngördük K, Asicioglu O, Celikkol O, et al. Use of additional oxytocin to reduce blood loss at elective cesarean section: a randomized control trial. Aust N Z J Obstet Gynaecol. 2010;50(1):36-39.

4. Chassard D, Bouvet L. Administration of tranexamic acid to reduce maternal mortality related to postpartum haemorrhage: comments on the WOMAN trial. Int J Obstet Anesth. 2018;33:89-90.

5. Cesarean Section. Clinical Guideline. National Collaborating Centre for Women's and Children's Health. London: RCOG Press;2004. 282 p.

6. Bolton TJ, Randall K, Yentis SM. Effect the confidential enquriries into maternal deaths on the use of syntocinon at cesarean section in the UK. Anesthesia. 2003;58(3):277-279.

7. Prentice A. Fortnightly review. Medical management of menorrhagia. BMJ. 999;319(7221):1343-1345.

8. Brown RS, Thwaites BK, Mongan PD. Tranexamic acid is effective in decreasing postoperative bleeding and transfusions in primary coronary artery bypass operations: a double-blind, randomized, placebo-controlled trial. Anesth Analg. 1997;85(5):963-970.

9. Ido K, Neo M, Asada Y, et al. Reduction of blood loss using Tranexamic acid in total knee and hip arthroplasties. Arch Orthop Trauma Surg. 2000;120(9):518-520.

10. Dunn CJ, Goa KL. Tranexamic acid: a review of its use in surgery and other indications. Drugs. 1999;57(6):1005-1032.

11. Ahmed MR, Sayed Ahmed WA, Madny EH, et al. Efficacy of tranexamic acid in decreasing blood loss in elective cesarean section. J Matern Fetal Neonatal Med. 2015;28(9):1014-1018.

12. Movafegh A, Eslamian L, Dorabadi A. Effect of intravenous tranexamic acid administration on blood loss during and after caesarean delivery. Int. J.Gynecol. Obstet. 2011;115(3):224-226.
13. Gai MY, Lian fang Wu, Qi fengs Su, et al. Clinical observation of blood loss reduced by tranexamic acid during and after caesarian section: a multi-center, randomized trial. Eur J. Obstet. Gynecol. Reprod. Biol. 2004;112(2):154-157.

14. Leila Sekhavat, Tabatabaii A, Dalili M, et al. Efficacy of tranexamic acid in reducing blood loss after cesarean section. J of Mater-Fetal \& Neon Med. 2009:22(1):72-75.

15. Baird EJ. Identification and management of obstetric hemorrhage. Anesthesiol Clin. 2017;35(1):15-34.

16. Bresnoc, et al. Tranexamic acid in postpartum hemorrhage. Br. J Obstet. Gynecol. 1996; 102(12):1250-1251.

17. Gohel M, Purvi P, Ashoo G,et al. Efficacy of tranexamic acid in reducing blood loss during and after the lower segment cesarean section: A randomized case controlled prospective study. Obstet. Gynecol. India. 2007;50(3);228-230.

18. Yang H, Zheng S, Shi C. Clinical study on the efficacy of tranexamic acid in reducing postpartum blood loss: a randomized, comparative, multicenter trial] [in Chinese]. Zhonghua Fu Chan Ke Za Zhi. 2001;36(10):590-592.

19. Prentice A. Fortnightly review. Medical management of menorrhagia. BMJ. 1999;319(20):1343-1345.

20. Rani PR, Begum J. Recent advances in the management of major postpartum haemorrhage. J Clin Diagn Res. 2017;11(2):QE01-QE05.

21. Henry DA, Moxey AJ, Carless PA, et al. Anti-fibrinolytic use for minimizing perioperative allogeneic blood transfusion. Cochrane Database Syst. Rev. 2001;19(1):CD001886.

22. Svanberg L, Astedt B, Nilsson IM, et al. Abruptio placentae $\square$ treatment with the fibrinolytic inhibitor tranexamic acid. Acta Obstet Gynecol Scand. 1980;59(2):127-130.

23. Bekassy Z, Astedt B. Treatment with the fibrinolytic inhibitor tranexamic acid risk for thrombosis. Acta Obstetricia et Gynecologica Scandinavica. 1990;69(4):353-354. 